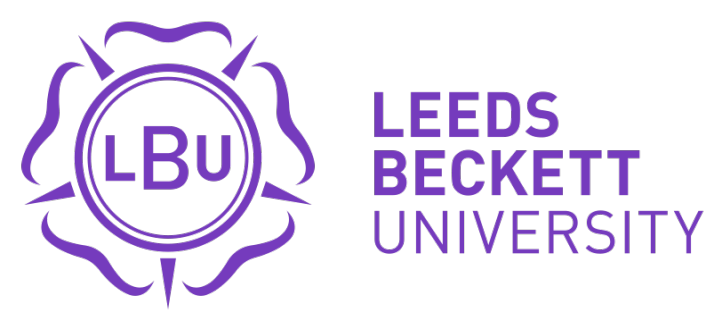

Citation:

Glyptou, K and Paravantis, JA and Papatheodorou, A and Spilanis, I (2014) Tourism sustainability methodologies: A critical assessment. IISA 2014 - 5th International Conference on Information, Intelligence, Systems and Applications. pp. 182-187. DOI: https://doi.org/10.1109/IISA.2014.6878832

Link to Leeds Beckett Repository record:

https://eprints.leedsbeckett.ac.uk/id/eprint/3288/

Document Version:

Article (Accepted Version)

The aim of the Leeds Beckett Repository is to provide open access to our research, as required by funder policies and permitted by publishers and copyright law.

The Leeds Beckett repository holds a wide range of publications, each of which has been checked for copyright and the relevant embargo period has been applied by the Research Services team.

We operate on a standard take-down policy. If you are the author or publisher of an output and you would like it removed from the repository, please contact us and we will investigate on a case-by-case basis.

Each thesis in the repository has been cleared where necessary by the author for third party copyright. If you would like a thesis to be removed from the repository or believe there is an issue with copyright, please contact us on openaccess@leedsbeckett.ac.uk and we will investigate on a case-by-case basis. 


\section{Tourism Sustainability Methodologies: A Critical Assessment}

\author{
Kyriaki Glyptou \\ Department of Business Administration \\ University of the Aegean \\ Chios, Greece \\ k.glyptou@fme.aegean.gr
}

John A. Paravantis

Department of International \& European Studies

University of Piraeus

Piraeus, Greece

jparav@unipi.gr

\author{
Andreas Papatheodorou \\ Department of Business Administration \\ University of the Aegean \\ Chios, Greece \\ a.papatheodorou@aegean.gr
}

\author{
Ioannis Spilanis \\ Department of Environment \\ University of the Aegean \\ Mytilene, Greece \\ ispil@aegean.gr
}

\begin{abstract}
In an era of economic crisis and serious environmental constraints, the transition to sustainability enters dynamically the debate over long-term preservation and welfare at a systemic level. Tourism is a resource- (capital, human and natural) demanding sector; this paper explores the variety and diversity of methodological approaches and tools employed in the evaluation of tourism, and their potential to support sustainability-oriented assessments and practices. Ranging from traditional economics-oriented frameworks to assessments of impact and ecological footprint, this paper discusses the prevailing assessment frameworks of specific tourism dimensions heading towards the integrative approaches for Tourism Sustainability Assessment. The review highlights that despite the widespread acceptance of the concept and the international consensus on the importance of its operationalization, the transition towards tourism sustainability remains still a complicated and rather problematic endeavour.
\end{abstract}

Keywords-Tourism, Sustainability Assessment, Operationalization, Evaluation Frameworks, Review.

\section{INTRODUCTION}

The developmental pattern of Ssustainability has been promoted over the last two decades, by the academic [1-2] and institutional community [3-5] as a high priority objective and as a prerequisite for any effective planning and policy actions of the tourism sector and its hosting destination. Despite the numerous theoretical approaches on the conceptualization and measurement of the notion, this paper suggests that little progress has been made towards its actual operationalization. The difficulty lies primarily in the absence of explicit quantitative targets and benchmarks of tourism sustainability as well as the inability to develop concrete, generalized and applicable guidelines towards its achievement and measurement.

In an effort to contribute towards the identification of the occasional discrepancies between tourism assessment tools and sustainability assessment, the paper provides an overview of existing methodologies and frameworks; highlights their strengths and weaknesses; and identifies major pitfalls towards the actual operationalization of tourism sustainability. The paper is structured in four sections. The first three summarize the methodologies and tools focusing on the assessment of individual dimensions of the tourism sector: economic, social and environmental. The last section presents all integrative methodologies and tools with respect to the evaluation of Tourism Sustainability. The paper concludes with a number of overall remarks on the findings of the presented review highlighting potential avenues for the concepts' operationalization.

\section{LITERATURE REVIEW}

\section{ECONOMIC DIMENSION OF TOURISM}

Tourism is primarily regarded as a production sector by the dominant literature, thus evaluated in terms of its contribution and impact through a pure economics-oriented perspective [68]. In contrast to the rest of the production sectors composing the System of National Accounts (SNAs), tourism is analyzed from the demand side implying that the required tourism consumption volume of goods and services (tourism demand) determines the size and dynamics of the production and resource units employed in the hosting economy (tourism supply) [7, 9-10]. In this context, supply is expected to be fully elastic and dependent on the demand (in terms of the quantity produced), notwithstanding the restricted availability and renewal capacity of the supporting natural resources. This approach is deeply rooted into the shortcomings of setting explicit boundaries to the tourism phenomenon as economic activity due to the great difficulty in: (a) identifying the numerous and multilevel (direct, indirect, induced and catalytic) interconnections of tourism with the rest of the production sectors, but mainly in (b) distinguishing between the end-user (tourist or not) of a tourism-characteristic product. As a result, tourism economics-oriented approaches are subject to reliability constraints regarding the complete extent of sectors' contribution and production line, with many 
academics and practitioners [11-15] calling for the need to develop more specialized methodologies and tools beyond the neoclassical model.

The prevailing economics-oriented methodology employs data from SNAs in order to approach tourism in one of the three following ways [7, 9-10]:

(a) As a production or service sector, included in the broader category of "Services" and thus impeding the differentiation of its inherent components; or as the sole category of "Hosting \& Alimentation Services", thus failing to capture the range of activities comprising tourism product.

(b) As a private consumption annually modulated sector indicating a separate category of final demand. As such, information is biased to the failure of final consumer clarification, yet fragmented into those sectors directly related to the activation of tourism (e.g. hospitality, catering and transport).

(c) As a specific production sector in the "central matrix" of the Balance of Payments. Such fiscal information, confines the sector's contribution to goods and services (Gross Domestic Product or GDP) requested by tourists in the context of consumer activity.

In view of these shortcomings, Tourism Satellite Accounts (TSAs) have been developed over SNAs as an empirical crosssectoral methodological tool for determining the annual size and contribution of economic sectors that are not defined as specific industries in SNAs. Currently, there are two prevailing efforts of TSAs: that of United Nations World Tourism Organization (UNWTO), officially recognized by the public national and international organizations and that of World Travel and Tourism Council (WTTC) in cooperation with Oxford Economics, a consulting company. Even though the adoption of the TSA methodology is still voluntary at national level both organizations provide detailed information for each country based on national statistical sources. Despite of being based on the same primary data sources, the two tools function independently as they follow completely different methodologies and assessment approaches, resulting in neither compatible nor comparable conclusions.

More specifically, the United Nations (UN) TSA supports solely the quantification of tourism's direct effect, as being limited to a descriptive record of those activities not considered as typical touristic. It thus, provides mere reference to the indirect and induced effects of tourism consumption failing to capture its spread contribution over the economic system. The TSA Methodology's Manual [7] suggests the complementary use of Input-Output Tables, General Equilibrium Modeling or tourism multipliers to ameliorate the assessment's reliability in this regard. Yet, one should keep in mind that such elaborated tools assume the use of a detailed Supply-Use Table (i.e. the breakdown of supply to market output) to allow for the individual identification of imported components of each sector of internal tourism consumption (or total tourism internal demand), as well as the various imported components of tourism gross fixed capital formation.
On the other hand, the WTTC TSA methodology [16-17] develops around the broader notion of "Travel \& Tourism" introducing the complementary concepts of Tourist Industry and Tourism Economy thus differentiating tourism's direct effects from overall impacts. The WTTC framework, though fully endorsing the conceptual approach of the UN, is developed over a macroeconomic consideration of Tourism GDP and a number of its selective components (e.g. personal consumption, investments, expenses, imports, exports) based on sophisticated econometric methods of evaluation and forecasting. As such, it limits to the sole evaluation of the financial flows of those selected GDP components [16-17] not enabling linkages to their specific production contributors according to the SNA recording. Moreover, in order to overcome data insufficiency (data sourced from SNA), WTTC often bases its estimates on a number of assumptions (e.g. adoption of common weighting factors for all countries) and extrapolation of historical trends, entailing a high risk of deviating from reality [16-18]. This problem is further exacerbated by the fact that the evaluation of the WTTC is conducted centrally without the active participation nor involvement of national stakeholders.

Despite the evolution in tourism data collection and methodological techniques, what becomes apparent over time is the emphasis on evaluating tourism's contribution based on monetary data (both financial flows and production factors) and the exclusion of elements not conforming to the basic structure of SNAs [6-8]. As such, both tools largely lack the adequate inclusion of quantitative descriptive tourism statistics, such as the detailed number of tourists (by nationality), nights spent, occupancy rates, and physical characteristics such as travel incentives, trip duration and transport modes which directly influence and differentiate its contribution. The only rudimentary recording of tourism's "physical magnitude" is recorded in Table 10 of UN TSA (Table of Non-Monetary Indicators), yet data is aggregated, not specialized and mainly not linked to the economic measures of the other TSA Tables. The TSA Manual [7] stipulates that physical non-monetary indicators are an important component of tourism assessment process and therefore should not be regarded as secondary elements of UN TSA. Currently, the interconnection of (monetary and physical) flows and performances is not always feasible, and there is no information supporting the diversification of performances per tourism product and profile that are necessary for planning. After all, it is essential to note that tourism flows provide necessary information for economic analyses as well as a means of verifying their validity and reliability.

\section{SOCIAL DIMENSION OF TOURISM}

In the same line of economics-oriented thinking, tourism employment is mainly approached as a production factor in the framework of SNAs [9]. Evaluation data stem in the InputOutput Tables, analyzing a sector's contribution from the demand side. The approach allows for convenience and comparability with the economic dimension, yet it adopts its inherent methodological shortcomings (solely direct contribution to economy and mere descriptive linkages with 
indirect and induced effects, failure to encompass tourism qualitative characteristics, inability to differentiate between tourism products and typologies). In this regard, the prevailing demand approaches turn insufficient to capture the specificities governing the concept of tourism employment as dictated by international statistic guidelines like EUROSTAT [21-22], since they fail to account for dominant patterns of the phenomenon such as: seasonality of demand, uneven geographical distribution and intensity, high rates of self, parttime or secondary employment, high rates of illegal and under-skilled labor.

To address the shortcomings arising from the use of SNA's and TSA's data in the assessment of tourism employment, a number of additional tools (Organization for Economic CoOperation and Development or OECD Employment Module, International Labor Office's Tourism Labor Accounting System or ILO T-LAS) [23-24] and techniques (multipliers, General Equilibrium Models or GEMs) [25] can be applied. Yet, the former have high demand on analytical data which are not always available or sometimes fail to capture the precise linkages between monetary (SNA-based) and physical parameters of tourism employment. The latter, are quite complex, also high-demanding on data, but mainly complicated when it comes to real-time applications (planning and policy making). WTTC Employment module on the other hand [26], differentiates between the employment effect and impact activated in Tourism Industry and Economy respectively, succeeding to provide the complete image of sector's contribution. Yet, WTTC evaluations $[17,26]$ occasionally employ homogeneous weighting factors among countries, while forecasts extrapolate historical tendencies of pure financial flows (income, investment costs, etc.) jeopardizing the accuracy and reliability of the assessment.

Overall, what is lacking from the prevailing assessment methodologies of tourism employment is the inclusion of its qualitative specificities particularly in reference to the social and demographic dimension of the hosting destination (population migration and emigration, active population, unemployment rates etc). OECD [23] stresses specifically that the sector's contribution to employment requires further investigation based on the experience of countries during tourism employment assessments and the integration of national characteristics (self, part-time or double but mostly undeclared employment) in order to capture its contribution in the broader socioeconomic context.

A complementary supply-oriented perspective is proposed by EUROSTAT [22, 27] though the analysis of tourism employment statistical data from national offices according to international standards and guidelines (NACE, i.e. the statistical classification of economic activities in the European Community). This approach allows for a more detailed and thorough evaluation of the specificities of tourism employment, yet it is subject to the basic limitation of accurate identification of directly activated tourism industries. Despite international guidelines, a clear-cut determination of Tourism Characteristic Industries is usually lacking due to the fragmentation of tourist expenditure on goods and services that are not purely tourism-oriented (consumed also by residents) [21-22, 27]. After all, temporal (seasonality) and geographical diversification of tourism employment, as well as the diversity of secondary data sources (census, private employment companies records etc.) question further the reliability of the evaluation. Consequently, both approaches are rather incompatible and fail to complementary synthesize the complete image of tourism employment in an economic territory. However, when consulted independently they provide different perspectives and analyses of the phenomenon.

\section{ENVIRONMENTAL DIMENSION OF TOURISM}

Chapter 4 (Protecting our Common Environment) of the United Nations Millennium Declaration in 2000 [28-29] raised concerns over ecosystems quality, natural resources' depletion and the need for better measurements of the environmental dimension of anthropogenic activities including tourism. Yet they focus primarily on the environmental cost of tourism production instead of the direct and substantial dependence of tourism supply on environmental resources. Dominant methodologies and tools of tourism footprint can be summarized in two main categories: those expressed through a series of physical (non-monetary) indicators and those assessing the environmental impacts of tourism in monetary units.

The first category includes methodologies such as Ecological Footprint Analysis [30-32], Eco-efficiency Analysis [33] and Environmental Impact Assessment [34] along with all those frameworks and tools developed over a series of Indicators and aggregated Indices. Their primary weakness lies on the communication of their results in different (occasionally even qualitative) units of measurement, resulting into the failure of capturing the overall image of environmental quality or degradation and most importantly, great difficulty of linkage and comparison with the other two dimensions. Moreover, physical units of measurement are often upon criticism on their potency to produce reliable analysis, as well as their ability to support policy applications effectively. The category of translating environmental contribution into monetary units includes methods such as Simulated Markets and Contingent Valuation [35], Market Price [36], Hedonic Property Values Typology [37] etc. The application of these methods raises primarily questions on the ethics of valuating (assigning specific value at market prices) non-tradable goods "of common use" (not subject to any scheme of property) like the environmental resources, which is further intensified taken the specificities of tourism product (seasonality, perishability, etc).

As a result, the international tourism community is directed over the latest years towards the development of integrative methods of economic and environmental assessment tools, such as the System of Integrated Environmental and Economic Accounts (SEEA) [38], the National Accounting Matrix including Environmental Accounts (NAMEA) [39] and the Economic and Environmental Satellite Accounting of Tourism [40]. Such methods follow the logic of Social Accounting Matrix (SAM) [39-41] and employ data from SNAs to illustrate the interactions between natural resources and economic activities as flows of natural and economic capital. In this regard, they support the combination of tourism 
consumption components with their environmental implications, while being measured either in physical or monetary units. Despite, their advantage in combining the different dimensions and implications of tourism, these methods raised criticism over their constraints to depict the non-apparent (financial and natural) capital flows which nevertheless consist an important element of an economic activity [41]. Further concern relates to the inherent limitations of the Input-Output pattern (static model of partial evaluation) to sufficiently assess a system of general equilibrium (in the broader sense) like the economic one [42]. After all, one should keep in mind that such integration of environmental factors in monetary evaluation frameworks foments the misconception that environmental values can be directly compared with other monetary indicators [43].

\section{TOURISM SUSTAINABILITY: AN INTEGRATIVE APPROACH}

A number of tools have been applied overtime for the sustainability assessment of the tourism sector, particularly in reference to the measurement of visitors' impact on the availability and quality of natural resources of the hosting destination. Carrying Capacity [44] and Limits of Acceptable Change [45] are among the first methodologies employed to assess the signs of environmental degradation, while maximizing tourist experience. Yet, such tools proved to offer more of a process for resource management and policy guidance, rather than an assessment tool of the state of sustainability in the tourism destination at stake [46-47].

The majority of sustainability assessment frameworks build on a series of (disaggregated or rarely aggregated) indicators [e.g. 48-50]. Their great number and variety suggests the lack of a consensus over the most appropriate process for the development of a universal indicator framework that allows for the analysis of the sustainability of a tourist destination, nor its design. In the majority of cases, the assessment process is developed through the integration of economic, social and environmental indicators into generalized frameworks mainly Pressure-State-Response or PSR and Driving Force-Pressure-State-Impact-Response or DPSIR [15, 50-51], and pertains to the perception on behalf of each researcher of the proper procedure for synthesizing information depending on the characteristics of the analysis and those of the destination under study. As a result, international literature is dominated by case-specific and dimension-oriented frameworks [52], while in fact there has been little progress in designing integrative and adequately generalized frameworks for sustainability [15, 19-20, 50]. As such, existing frameworks are limited to partial comparisons (variable by variable or criterion by criterion) failing to pave the way for a uniform composite measure of tourism sustainability beyond a mere measure of individual change. The difficulty stems partly from the multivariate nature of sustainability in combination with the difficulty of gathering the large volume and variety of information required for the evaluation particularly of its environmental dimension, e.g. fuel consumption patterns influencing tourism's operational footprint [30-32] and land-use changes [19-20].
Efforts of aggregated tourism indices like the Travel and Tourism Competitiveness Index [53] and the Tourism Penetration Index [54] include a number of parameters associated directly or indirectly with the wider tourism activity, without necessarily focusing on the evaluation of its sustainability performance. As a result, there is no direct and dynamic connection with sustainable development policies, but merely an assessment of competitiveness (maximized tourism performance) indicators. Moreover, these evaluation frameworks do not include scaled weighting factors that increase the level of assessment sensitivity; instead, significance is attributed to the sole criterion of selection on a dichotomous scale. Complementary, yet more sustainability oriented is the Sustainable Performance Index of Castellani and Sala [55]. The Index involves a more comprehensive framework of tourism sustainability assessment, enabling the assessment of proxy variables to cover the lack of data availability and allowing further for the assignment of significance variation of selected indicators. Unfortunately, the process is dependent solely on stakeholder judgment entailing high levels of subjectivity while the benchmarking of reference values (normalization process) is set based on national standards (different typology and spatial scale) distorting the case-differentiation of the assessment.

A more complete tool of tourism sustainability assessment is proposed by Ko [56-57] through the Maps of Tourism Sustainability (TSAMs). Both the Barometer of Tourism Sustainability (BTS) and the AMOEBA of Tourism Sustainability indicators (ATSI) offer a measure for the progress (change) of a destination towards sustainability, while allowing the graphic depiction of total and individual measures (system, dimensions, indicators). The main constraint of the tools lies again in the selection of destinationspecific indicators (reflecting particularities), limiting the ability of the tool to support dynamic (non-static) temporal and geographic comparisons. The latest is further aggravated by the determination of the scale of sustainability evaluation based on the empirical criterion local stakeholder, which on one hand, overcomes the necessity for significance variance of the selected indicators, while on the other hand it significantly increases the subjectivity of the evaluation framework and the difficulty of generalizing its application. After all, the inclusion of assessment indicators defined by the subjective perception of stakeholders entails further to the risk of local specialization (desirable under certain conditions), the negligence of important elements overseen by their interests or perception. Therefore, any framework including subjective evaluation criteria as part of their assessment process should further include an objective (statistic) procedure for the correction of potential discrepancies and vice versa [58-59].

The need for a dynamic operationalization of the concept of tourism sustainability meets perhaps its only application in the model of Johnston and Tyrell [60-61]. The proposed model employs complex mathematical processes to provide a generalized framework for achieving Sustainable Tourism beyond spatial focus. However, even in its simplified mathematical version it remains quite complex for direct application in planning and policy making by non-specialized users. Moreover, its very conceptual basis poses a number of 
concerns over the perception of continuous renewability of natural resources, notwithstanding its continuous and dynamic linkages with anthropogenic uses. Furthermore, the selection of the number of tourism arrivals as a control variable raises concern over its high sensitivity and unrealistic representation of the intensity of the tourism phenomenon. The aforementioned conceptual concerns may significantly alter the estimates of a time-dependent assessment model.

\section{CONCLUDING REMARKS}

For White et al. [62] the measurement of Tourism Sustainability is associated with the great paradox "whereby often we value what we can measure, rather than measuring what we value". The present review revealed a number of methodological and conceptual shortcomings jeopardizing concept operationalization. More specifically:

(a) There is still no common agreement on an adequately generalized framework of tourism sustainability assessment, due to the concept's inherent limitations.

(b) For the majority of assessment approaches, tourism is regarded as a "highly modulated final consumer demand activity", thus natural resources and human capital supply are expected to be fully elastic and unrestrained to the activated consumption patterns. This unbalanced integration of all three dimensions of sustainability puts in jeopardy the systemic nature of the phenomenon.

(c) The achievement of sustainability is usually communicated as an ideal (qualitative) state of the remote future. This perception restrains further the real-life operationalization of the concept into specific planning and decision making actions.

(d) There is no explicit differentiation and cause-effectimpact linkages among the elements defining the tourism profile of destination, the performance and direct effect of the sector per se, and the overall (direct, indirect, induced and catalytic) impacts entailed by the activity for the hosting destination.

(e) There is inadequate clarification between the concepts (and assessment frameworks) for Tourism Sustainability and Sustainable Tourism Development.

Despite the aforementioned constraints, Tourism Sustainability in an era of economic and resources crisis remains fundamentally a planning, managerial and policy objective. Considering the practical utility of its operationalization and measurement, a forthcoming publication will introduce a methodological structure and an operational tool in support of Sustainable Tourism Destination Management and Planning.

\section{REFERENCES}

[1] R.W. Kates, W.C. Clark, R. Corell, J.M. Hall, C.C. Jaeger, I. Lowe, J.J. McCarthy, H.J. Schellenhuber, B. Bolin, M. Dickson, S. Faucheaux, G. C. Gallopin, A. Grübler, B. Huntley, J. Jäger, N. S. Jodha, R.E. Kasperson, A. Mabogunje, P. Matson, H. Mooney, B. Moore, III T. O' Riordan and U. Svedin, "Sustainability Science," Science, vol. 292, 2001, pp. 641-642.
[2] T. O'Riordan, "Environmental science, sustainability and politics" in Transactions of the Institute of British Geographers, vol. 29, 2004, pp. 234-247.

[3] CEC, "Mainstreaming sustainable development into EU policies: 2009 Review of the European Strategy for Sustainable Development," Communication from the Commission to the European Parliament, the Council, the European Economic and Social Committee and the Committee of the Regions. Brussels, 24.7.2009(COM2009) 400 final.

[4] United Nations General Assembly, "Environment and sustainable development: implementation of Agenda 21 and the Programme for the Further Implementation of Agenda," 2. Report of the Second Committee. Fifty-seventh session Agenda item 87 (a). A/57/532/Add.1 [Online] 2002. http://daccess-ddsny.un.org/doc/UNDOC/GEN/N02/738/17/PDF/N0273817.pdf?OpenEle ment, accessed on 11/2012.

[5] CEC, "A Sustainable Europe for a Better World: A European Strategy for Sustainable Development," COM(2001) 264 final, Brussels: CEC.

[6] UNWTO, "Recommendations on Tourism Statistics," in Recommendations on Tourism Statistics (United Nations publication, Sales No. E.94.XVII.6), Part One. New York, 1994.

[7] UNWTO, "International Recommendations for Tourism Statistics 2008 (IRTS:2008)," UNWTO Department of Economic and Social Affairs Statistics Division, Madrid and New York, 2008.

[8] UNWTO, "Measuring the Economic Importance of the Meetings Industry: Developing a Tourism Satellite Account Extension.” UNWTO, Madrid, Spain, 2007.

[9] CEC, IMF, OECD, UN \& World Bank, "System of National Accounts 1993," Commission of the European Communities-Eurostat, International Monetary Fund, Organisation for Economic Co-operation and Development, United Nations and World Bank, Brussels/Luxembourg, New York, Paris, Washington, 1993, xlix +711 pp.

[10] CEC, IMF, OECD, UN \& World Bank, "System of National Accounts 2008," Commission of the European Communities-Eurostat, International Monetary Fund, Organisation for Economic Co-operation and Development, United Nations and World Bank, Brussels/Luxembourg, New York, Paris, Washington, 2008.

[11] B.Y.Ahn, B.K. Lee and S. Shafer, "Operationalizing sustainability in regional tourism planning: an application of the limits of acceptable change framework," Tourism Management, vol. 23, 2002, pp.1-15.

[12] K. Brickley, R. Black and S. Cottrell (Eds),. "Sustainable Tourism and Millennium Development Goals," Jones \& Bartlett Learning: Burlington, MA, USA, 2013.

[13] UNWTO, "UNWTO's Declaration on Tourism and the Millennium Goals: Harnessing Tourism for the Millennium Development Goals," UNWTO: Madrid, Spain, 2006.

[14] J. Saarinen, "Critical Sustainability: Setting the Limits to Growth and Responsibility in Tourism," Sustainability, vol.6, 2014, pp.1-17.

[15] J.I. Pulido Fernandezand, and M.S. Rivero, "Measuring tourism sustainability: proposal for a composite index," Tourism Economics, vol. 15, Issue 2, 2009, pp.:277-296.

[16] WTTC and OE, "Methodology for producing the 2008 WTTC/OE Travel \& Tourism Simulated Satellite Accounts," World Travel \& Tourism Council \& Oxford Economics, March 2008.

[17] WTTC,"Methodology for producing the 2013 WTTC/Oxford Economics Travel \& Tourism Economic Impact Research,"Oxford, UK: WTTC and Oxford Economics, February 2013.

[18] UNWTO,"Measuring Tourism: The UN-TSA approach vs the WTTC approach," Report prepared by the Department of Statistics and Tourism Satellite Account (TSA), Madrid, Spain, September 2008.

[19] I. Spilanis and J. Le Tellier, "Towards an Observatory and a "Quality Label" of Tourism Sustainability in the Mediterranean," Plan Blue, UNEP/MAP Regional Activity Centre, 2012.

[20] K. Glyptou, "Tourism Destination Management by means of Sustainability Assessment and Forecasting models," $\mathrm{PhD}$ Thesis, University of the Aegean, 2014. 
[21] EUROSTAT, "Community Methodology on Tourism Statistics," Office for Official Publications of the European Communities, Luxemburg, 1998

[22] EUROSTAT, "Methodological Manual for Tourism Statistics," Version 1.2., Luxembourg, 2012.

[23] OECD, "Measuring the Role of Tourism in OECD Economies: The OECD Manual on Tourism Satellite Accounts and Employment," Paris, France 2000, Vol. 2.

[24] ILO, "An Introduction to Labor Statistics in Tourism," Geneva, June2004, http:statistics.unwto.org/sites/all/files/pdf/ilo b eng.pdf, accessed on 12/13.

[25] M.J. Stabler, A. Papatheodorou and M.T. Sinclair, "The economics of tourism," London: Routledge Second Ed. 2010.

[26] WTTC, "Travel \& Tourism as a Driver of Employment Growth," in The Travel and Tourism Competitiveness Report 2013, Chapter 1.5. 2013 World Economic Forum.

[27] EUROSTAT, "The Eurostat Manual on Employment in Tourism.” Nico Heerschap (ed), First draft, V.2. 2002.

[28] UN, "United Nations Millenium Declaration," The General Assembly, September 8, 2000.

[29] UNDP, UNEP, World Bank, and WRI, "World Resources: People and Ecosystems," WRI, Washington DC.2000.

[30] M. Wackernagel and D. Yount, "The Ecological Footprint: an Indicator of Progress towards Regional Sustainability," Environmental Monitoring and Assessment, vol.51, 1998, pp.511-529.

[31] M. Wackernagel and A.Galli, "An overview on ecological footprint and sustainable development: a chat with Mathis Wackernagel," International Journal of Ecodynamics, vol.2(1), 2007, pp. 1-9.

[32] S. Gössling, C. Borgström Hansson, O. Horstmeier and S. Saggel, "Ecological footprint analysis as a tool to assess tourism sustainability," Ecological Economics, vol.43, 2002, pp.199-211.

[33] L.D. de Simone and F. Popoff with WBCSD, “ Eco-efficiency: the Business Link to Sustainable Development," Cambridge, MA: MIT Press, 1997.

[34] UN Environment and Economics Unit, "Environmental Impact Assessment: Issues, Trends and Practice," Scott Wilson Ltd.,1996 Nairobi, Kenya.

[35] R.C. Bishop, T.A. Heberlein and M.J. Kealy, "Contigent valuation of environmental assets: Comparisons with simulated markets," Natural Resources Journal, vol.23(3), pp.619-633.

[36] A.M. Freeman, "The Measurement of Environmental and Resource Values: Theory and Methods. Resources For the Future," Washington, D.C. 1993 .

[37] M. Munasinghe, "Environmental Economics and Sustainable Development, Paper presented at the UN Earth Summit, Rio de Janeiro, Environment Paper No.3, World Bank, Wash. DC, USA.1992.

[38] UN, EC, IMF, OECD and WB, "Handbook of National Accounting: Integrated Environmental and Economic Accounting 2003 (SEEA 2003)." Studies in Methods, Series F, No.61, Rev.1 (ST/ESA/STAT/SER.F/61/Rev.1). United Nations, New York, 2003.

[39] P. Kee, and M. de Haan, "Accounting for Sustainable Development", Statistics Netherlands, Division of Macro-economic Statistics and Dissemination Development and support Department. Centraal Bureau voor de Statistiek, 2004

[40] Y. Rueda Calderon, A. Blake, and W. Chapple, "Economic and Environmental Satellite Accounting of Tourism: A proposed Framework,' In Enzo Paci Papers vol.6, 2009, UNWTO Publications.

[41] S. Santos, "The importance of Social Accounting Matrix. Application to Portugal during the 1990-95 period," ISEG-TULisbon-Department of Economics' Seminar, Lisbon, Portugal, 2001.

[42] L. Dwyer, P. Forsyth, and R. Spurr, "Evaluating Tourism's Economic Effects: New and Old Approaches," Tourism Management, vol. 25, 2004, pp.307-317.

[43] J.E.Stiglitz, A. Sen and J.P. Fitoussi, " Report of the Commission on the measurement of economic performance and social progress," April 2223, 2008, Paris, France, [Online] http://www.stiglitz-senfitoussi.fr/documents/rapport anglais.pdf, accessed on 12/13.
[44] UNEP, MAP and PAP/RAC, "Guidelines for carrying capacity assessment for tourism in Mediterranean coastal areas," RAC Reports (PAP) PAP-9/1997 G.1. Priority Actions Programme Regional Activity Centre: Split.

[45] G.H. Stankey and D.N. Cole, "The Limits of Acceptable Change (LAC) System for Wilderness Planning", USDA Forest Service Intermountain Research Station: Ogden, UT, 1985.

[46] V.D. Abernethy, "Carrying capacity: the $\mathrm{t}$ radition and policy implications of limits," Ethics in Science \& Environmental Politics, vol. 23, 2001, pp. 9-18.

[47] R.W. Butler, "The concept of carrying capacity for tourism destinations: Dead or merely buried? Progress in Tourism and Hospitality Research," vol.2, 1996, pp. 283-293. (Article first published online: October 15th, 2012 in the International Journal of Tourism Research).

[48] Commission on Sustainable Development, "Indicators of Sustainable Development: Framework and Methodologies." Ninth Session: 16-27 April, 2001, New York. Background Paper No 3. DESA/DSD/2001/3.

[49] S.F. McCool and G.H. Stankey, "Indicators of sustainability: challenges and opportunities at the interface of science and policy," Environmental Management, vol. 33(3), 2004, pp. 294-305.

[50] UNWTO, "Indicators of Sustainable Development for Tourism Destinations: A Guidebook." WTO, Madrid. 2004

[51] U. Muzaffer, M.J. Sirgy and R. Perdue (eds), "Handbook of Tourism and Quality-of-Life Research: Enhancing the Lives of Tourists and Residents," Dordrecht, Netherlands: Springer Publishers, 2012.

[52] H. Xiao and S.L.J.Smith, "Case studies in tourism research: A state-ofthe-art analysis," Tourism Management, vol.27(5), pp.738-749.

[53] WEF, "The Travel \& Tourism Competitiveness Report 2009: Managing in a Time of Turbulence," World Economic Forum: 2009.

[54] J.L. McElroy and K. de Albuquerque, "Tourism penetration index for the small-island Caribbean," Annals of Tourism Research, vol. 28, 1998, pp. $145-168$.

[55] V. Castellani and S. Sala, "Sustainable Performance Index for tourism policy development,", Tourism Management, vol.31(6), 2010, pp. 871880.

[56] J.T.G. Ko, "Assessing progress of tourism sustainability," Annals of Tourism Research, vol. 28 (3), 2001, pp. 817-820.

[57] J.T.G. Ko, "Development of a tourism sustainability assessment procedure: a conceptual approach," Tourism Management, vol. 26, 2005, pp. 431-445.

[58] G.P. Baker, "Incentive contracts and performance measurement," Journal of Political Economy, vol.100, 1992, pp. 598-614.

[59] A. Suvorov and J. van de Ven, "Discretionary rewards as a feedback mechanism," Games and Economic Behavior, vol.67, 2009, pp. 665681.

[60] R. Johnston and T. Tyrrell, "A Dynamic Model of Sustainable Tourism," Journal of Travel Research, vol. 44(2), 2005, pp. 124-134.

[61] R. Johnston and T. Tyrrell, "Tourism sustainability, resiliency and dynamics: Towards a more comprehensive perspective," Tourism and Hospitality Research, vol. 8, 2008, pp. 14-24.

[62] V. White, G. McCrum, K.L. Blackstock, and A. Scott, "Indicators and Sustainable Tourism: Literature Review," Aberdeen: Macaulay, Institute, 2006. 